\title{
MEMORIA HISTÓRICA Y HUMANISMO: LA ÉPOCA DE LOS REYES CATÓLICOS EN LOS POEMAS MITOGRÁFICOS DE JUAN DE MAL LARA
}

Francisco J. Escobar Universidad de Sevilla

Durante el proceso de composición de sus poemas mitográficos, Juan de Mal Lara (1526-1571) tiene en cuenta, como una notable referencia, los grandes imperios del pasado. ${ }^{1}$ Estos testimonios históricos conllevan un período de florecimiento cultural, in illo tempore, en el que los hombres de letras pudieron desarrollar, en el entorno áulico, su actividad. Mal Lara, por su parte, puso sus obras al servicio de la monarquía, recreando la evocación de reinados, con los que podía comparar los protagonizados por Carlos V, Felipe II, así como la regencia coyuntural de Juana de Austria, a quien está dedicada La Psique. Entre tales hitos, ocupa un lugar preeminente la época de los Reyes Católicos. Una de las razones de dicha elección obedece a la continuidad del Imperio, iniciado con los reyes Isabel y Fernando, en las figuras de los Monarcas en tiempos de nuestro escritor. En virtud de la translatio imperii, el reinado hispánico se convierte en heredero, a su vez, de las civilizaciones de la Antigüedad, especialmente, las representadas por Grecia y Roma. Y Sevilla, en la Weltanschauung del humanista, se erigirá, en fin, como una noua Roma, en la que Mal Lara se alza como el vate regio, al modo de un Virgilio.

Otro argumento que debió contemplar Mal Lara reside en el amplio abanico de posibilidades que esta época le ofrecía en su praxis discursiva. Según veremos, en dicho período, sobresalen las voces de humanistas que dejarán su huella en la forma mentis del hispalense. Podemos traer a colación los nombres de Nebrija, Marineo Sículo o Anglería. Éste último, sobre todo, despliega, ante los ojos del escritor, un panorama revelador para su obra en lo relativo a la literatura de viajes. Tal hecho le permite la conjugación de elementos heterogéneos tomados de la realidad con otros fabulosos. Sus personajes emprenderán, de este modo, un camino iniciático, en el que habrán de protagonizar arriesgadas aventuras, teniendo como correlatos destacadas figuras en decorados míticos. Pasemos seguidamente al análisis de estas cuestiones.

1 Se trata de dos manuscritos inéditos de los que estamos preparando actualmente la edición, ya en fase avanzada. El Hércules animoso se encuentra en mal estado por la oxidación de la tinta galometálica. Fue localizado por José Cebrián, "En torno a una epopeya inédita del siglo XVI: El Hércules animoso de Juan de Mal Lara", Bulletin Hispanique, 91 (1989), págs. 365-93. Por nuestra parte, insistimos en el contenido de la Tabla, que había pasado desapercibida: "Una enciclopedia erudita desconocida del siglo XVI: la Tabla del Hércules animoso, de Juan de Mal Laras, en Memoria de la palabra. VI Congreso de la AISO, ed. $\mathrm{M}^{\mathrm{a}}$ Luisa Lobato y Francisco Domínguez, Madrid/Frankfurt am Main, Iberoamericana/Vervuert, 2004, págs. 737-50; y eNuevos datos sobre libros y lecturas de Juan de Mal Lara (A propósito de la Tabla de autores del Hércules animoso), Criticón, 90 (2004), págs. 79-98. Para La Psique cf. nuestro libro El mito de Psique y Cupido en la poesía española del siglo XVI, Sevilla, Universidad, 2002, págs. 77-169. Transcribimos los textos, conservando el sistema ortográfico original, desarrollando las abreviaturas y modernizando la puntuación y la acentuación. Se regulariza el uso de mayúsculas y minúsculas. 


\section{EVOCACIÓN DE LA MEMORIA HISTÓRICA: ENTRE LA REALIDAD Y LA LEYENDA}

El interés de Mal Lara por este período se materializa, en primer lugar, en la recuperación de la memoria histórica concerniente a los Monarcas, a modo de semblanzas laudatorias. En la entrada cathólicos de la Tabla del Hércules, menciona el origen griego del término para aplicar su significado al caso de los Reyes; el valor ejemplar se encuentra supeditado a la custodia y vigilancia de la Fe cristiana. Tal atención a la espiritualidad la considera Carlos V un precioso legado, al decir de Mal Lara. Ello justifica que en la aclaración alegórica de los trabajos de Hércules, uno de los preliminares del poema, se aluda al seguimiento de estas leyes por parte del Emperador. La referencia se encuentra en la explicación del libro II, dedicado a la Hidra, metáfora circunscrita a los herejes que atentan contra la Iglesia Católica. Como en el paratexto, la deuda contraída por Carlos V para con los Reyes Católicos recibirá, además, un tratamiento poético en el Hércules. De esta suerte, la vehemencia del Monarca a la hora de paliar los vicios humanos es parangonable a la de Isabel I, según expresa Mal Lara en el canto III del libro II, recordando el tema de la mujer fuerte (129-136). Dicho leitmotiv lo habrá de continuar nuestro escritor en el libro XI de La Psique (994-997), en el que el vaticinio de Proteo, con influencias del De Partu Virginis, de Sannazaro, da pie a la mención de la ilustre genealogía. En el texto, Mal Lara hace entroncar nuevamente la acmé de los Reyes Católicos con la gloria conseguida por Carlos V. Estas figuras vienen a engrosar, pues, una dinastía de monarcas, que el poeta remonta al pasado legendario de civilizaciones remotas y de noble abolengo.

La evocación de este floruit político exige el recuerdo de conocidos personajes de la época. Se lleva la palma, en buena medida, el capitán Pedro Navarro (1460-1528), conde de Oliveto, ensalzado por sus batallas en beneficio del Imperio. A él le dedica Mal Lara sendas entradas del Hércules. La primera de ellas (conde Navarro) la concibe como una sucinta semblanza, pero en la que recoge los datos más representativos de su retrato. Entre sus habilidades destaca la de ser «ingeniero" de minas terrestres militares. El ítem Trípol constituye, en cambio, una amplificatio de la entrada mencionada, puesto que insiste en la conquista de Trípoli en 1510 por Navarro. Mal Lara pone de manifiesto, entre otras cosas, su añoranza de esta hazaña, ya que, cuando está redactando el vocablo (ca. 1565), el Imperio no cuenta con la plaza obtenida antaño.

Pero no siempre relaciona el humanista sus semblanzas con la rememoración de batallas y otros acontecimientos de alto vuelo. A veces, habrá de esbozar el retrato del personaje a partir de una anécdota híbrida entre la realidad y la ficción, entre lo culto y lo popular. Sucede con el elogium del caballero "Don Manuel", quien, como un nuevo Cid, demostrará su valentía, exponiendo la vida para ayudar a una dama a recuperar el guante que había dejado caer, ex profeso, en una jaula de leones:

Un valeroso cauallero, hermano del marqués de Cáliz. Padre del primer conde de Bailén, de quien se cuenta auer entrado en el corral de los leones del Rey Don Fernando el Cathólico, que estauan en el Alcáçar de Seuilla, por un guante que se le cayó a una dama, que, por exprimentar el valor de Don Manuel, lo dexó caer entre los leones. Y él valerosamente entró y, sacándolo de allí; lo dio a la dama con una reprehensión que le hizo, porque no pusiesse a los caualleros en peligro sin propósito (D. Manuel).

El texto tiene como protagonista a Manuel Ponce de León, apodado El Valiente. ${ }^{2}$ Fue hijo de Juan Ponce de León, conde de Arcos, y Leonor Núñez, así como hermano de Rodrigo Ponce de León, Marqués de Cádiz, con el que mantuvo cierta rivalidad durante la toma de Marchena en 1473. Si D. Rodrigo fue comparado con el Cid -como demuestra la anónima Historia de los bechos del Marqués de Cádiz-,3 D. Manuel sufrió una suerte de damnatio memoriae, seguramente por

2 Juan Carriazo, "Manuel Ponce de León el Valiente, un personaje entre la historia y la leyenda", en $N$ Estudios de Frontera, ed. Francisco Toro, Jaén, Diputación, 2001, págs. 109-27.

3 Editada por Carriazo, Granada, Universidad, 2003; con bibliografia sobre esta dinastía. Un análisis de tal comparación ofrece Angus Mackay, «Un Cid Ruy Díaz en el siglo XV: Rodrigo Ponce de León, marqués de Cádiż, en El Cid en el valle del Jalón, Calatayud, Centro de Estudios Bilbilitanos, 1991, págs. 197-207. 
los turbios avatares que rodearon su vida, entre ellos, un encarcelamiento al reclamar la sucesión, tras el fallecimiento de su hermano. No obstante, contamos con testimonios en los que se le pondera -aunque sin la mención de la anécdota del león-, como el de Marineo en De Hispaniae Laudibus. ${ }^{4}$ Pero aunque la historia relegase a donde babite el olvido al Valiente, en cambio, por vicisitudes no muy claras, éste último habría de cobrar un protagonismo inusitado como personaje legendario, materia que interesó a Mal Lara. El elemento fabuloso había asentado, en este sentido, ya su semilla en los cimientos históricos de la familia, puesto que D. Manuel puso el nombre de Roldán a un hijo suyo que tuvo con Guiomar de Castro, rememorando el linajudo abolengo literario de su antepasado homónimo. Con ello le obligaba, en cierta medida, a emprender hazañas (que no llegaron a buen fin, dada su demencia). Partiendo de tales principios, Roldán llegó incluso a considerar abuelo al personaje literario, mientras que identificaba a su tío Rodrigo con el Cid. La propia vida íntima de D. Manuel estuvo rodeada, igualmente, de cierta leyenda entre caballeresca y cortesana, adquiriendo fama por sus galanteos palaciegos ${ }^{5}$ (de ahí el apunte del guante de la dama). Y la presencia de leones, con los que compara la Historia a Rodrigo, representa un símbolo que figura en el blasón de los Ponce. En el pasaje de Mal Lara, se asociará, en cambio, a D. Manuel, en tal anécdota, de raíces folclóricas, que se había fraguado en el segundo cuarto de siglo, como muy tarde.

En efecto, el texto entronca con una floreciente tradición que parte de Sánchez de Badajoz, auctor leído por el hispalense (Hércules, IV, 3, 89-96), quien en la última estrofa dedicada a amadores en el Infierno de amor (1511), apunta el episodio. Con el paso del tiempo, la leyenda se fue convirtiendo en un granado símbolo del romancero fronterizo. Con seguridad, en los romances viejos, que despertaron la curiosidad de Mal Lara (según recuerda en el Hércules), se fue gestando la historia hasta cristalizar en las composiciones insertas en Rosa Gentil, de Timoneda (1573) o en la Segunda parte de la Sylva, recopilada por Mendaño (1588). Prueba de esta consolida-ción del episodio en la primera mitad del XVI lo constituye la intercalación de una estrofa sobre el tema en el canto XXIV, en la traducción del Orlando furioso (1549) por Urrea. ${ }^{6}$ Por las mismas fechas, Oviedo, primer cronista de Indias, evoca el episodio en el diálogo XXVIII de las Batallas y Quincuagenas (I, 3), pero situándolo en Segovia, durante el reinado de Enrique IV. Nuestro texto viene a preludiar, en fin, el éxito que tuvo la anécdota en testimonios posteriores como el de Argote, en la Nobleza de Andalucia (1588), así como el de López de Haro, en el Nobiliario (1622), los realizados por Mira de Mescua y Lope de Vega, en el género dramático, en sus obras Galán, valiente y discreto, y El guante de doña Blanca, que incorporan el motivo como parte de su trama, o el mismo Cervantes, como brillante culminación, en el episodio del carro de los leones (II, 17), en el que compara a D. Quijote con Manuel Ponce por una hazaña similar. $^{7}$

En lo concerniente a la diátaxis del pasaje, adoptará Mal Lara la perspectiva de un cronista en aras de ofrecer una sucinta laus de D. Manuel. Para ello omite los datos históricos más comprometidos en relación a las revueltas de El Valiente por ambición, rememorando, en su lugar, los motivos fundamentales del episodio legendario. El fragmento silencia dos elementos que figuran en otros textos de este sesgo: el nombre de la dama (Ana de Mendoza), así como la supuesta bofetada que recibió ésta -cuyo origen obedece a un lance protagonizado por Alonso Enríquez y Juana de Mendoza-, sustituida aquí por una «reprehensión». Mal Lara se hace eco, por otra parte, del rumor popular, como evidencia que maneje la fórmula use cuentan, en un uso afín a las formas latinas legitur o dicitur, empleadas por los historiadores clásicos que refieren un hecho 
del que tienen noticias mediante fuentes orales. El texto ofrece, en definitiva, un nuevo eslabón en esta cadena de testimonios para comprender la pervivencia del motivo en nuestra literatura áurea.

\section{HUMANISMO Y REELABORACIÓN MITOGRÁFICA: DE LOS AUCTORES Y SUS FUENTES}

El itinerario de Mal Lara por esta época complementa la fortitudo de las acciones bélicas con la sapientia de los hombres de letras. Encontramos, por ello, varios apuntes sobre poetas y humanistas en diversos vocablos. De Rodríguez del Padrón elogia su vertiente literario-musical (Ioan Rodrígves del Padrón). Como él, otras figuras desfilarán por el Hércules, adquiriendo protagonismo el cardenal Cisneros. Dos entradas esboza a fin de homenajear, en esta galería de retratos, su memoria. En Fray Francisco Ximenes, se ponen de relieve sus empresas más relevantes, como la edificación de la Universidad de Alcalá, recordando, al tiempo, su relación con el ya referido Navarro. Idéntico motivo habrá de constituir la piedra angular de la entrada Alcalá de Henares; en la que se insiste, una vez más, en este hecho. Junto a Cisneros, Mal Lara incluye la lauidatio de Nebrija, de quien se considera discípulo por sus libros (Antonio de Nebrissa). En la praxis poética del Hércules, lo encumbra en una relación de humanistas que influyeron en su formación, en compañía del Comendador Griego. El texto, inserto en IV, 1 (193-200), presenta notables problemas para su lectura por la conservación del manuscrito. Sea como fuere, Mal Lara nombrará a Nebrija, en determinados pasajes, en calidad de auctoritas que aclara la cuestión planteada. Lo observamos en el vocablo xantbo, con el que explica la referencia geográfica, haciendo alusión tanto a Marcial como al propio Nebrija. Ahora bien, no siempre estará de acuerdo Mal Lara con su modelo, de manera que ofrece, a modo de aemulatio, una lectura alternativa en algunos vocablos. Para ello, se vale de otros auctores, que vienen a apoyar su hipótesis. Sucede en el ítem Budinos, en el que, al margen de dilucidar la referencia etnológica, se aduce la autoridad de Nebrija frente a otros nombres como los de Heródoto o Mela, que avalan su excurso. Recuerda, por último, Mal Lara una "enmienda" del Comendador Griego al texto de Mela.

Además de Nebrija, dos humanistas serán citados en relación a esta época: Marineo y Anglería. Mal Lara se sentía, pues, atraído por el magisterio que tales hombres de letras ítalos ejercieron durante el reinado de los Reyes Católicos. De Marineo tuvo en cuenta sus Cosas memorables de Hespaña, según observamos en $D$. Ysabel. El texto presenta una alabanza de Isabel I, elogiando, igualmente, la labor de Marineo como cronista. El hispalense adoptará, por añadidura, esta técnica narrativa en su pasaje, de suerte que relata un hecho de gran magnitud que sucedió en Sevilla, en concreto, el enlace nupcial en 1526 entre Carlos V e Isabel de Portugal. ${ }^{8}$ Ofrece, en este contexto, unos valiosos datos que permiten precisar la fecha de su nacimiento, incierta hasta el momento. De hecho, recuerda cómo se encontraba en brazos de su madre el día del ilustre casamiento, revelando que había nacido la víspera de San Sebastián (19 de enero). Por tanto, el año que se viene aduciendo hasta la fecha (1524) da paso al mencionado, 1526:

Nombre de la reyna más valerosa que ha auido en Hespaña. Hija del rey Don Iuan el Segundo y de Doña Ysabel, nieta del rey de Portugal; porquel rey Don Ioan auía casado primero con Doña María, hija de Don Fernando, su tío, de quien uuo dos hijas, que murieron niñas, y al rey Don Henrrique, que fue quarto deste nombre. $Y$ de la segunda muger, uuo a Doña Ysabel y a Don Alonso, el qual, siendo de catorze años, fallesció no sin sospecha de ponçoñas. Nasció esta valerosa reyna en Madrigal, que está de Salamanca casi doze leguas, año de mil e quatrocientos y quarenta y nueue. Casó con el rey Don Fernando, de quien auemos tratado. De la vida destos Cathólicos y bien auenturados Príncipes, trata Sículo Marineo todo lo que vio y supo verdaderamente en el lib. 19 y 20 de su Historia o Cosas memorables de Hespaña. Uuo también deste nombre, la Emperatriz, muger que fue del inuictíssimo Carlos, hija de Don Manuel, rey de Portugal, cuyos casamientos se celebraron en la muy noble y leal cibdad

s Para los pormenores de tales nupcias, véase Mónica Gómez, Fastos de una boda real en la Sevilla del Quinientos, Sevilla, Universidad, 1998. 
de Seuilla, año del Señor de mil e quinientos y veynte seis por março en la Alcáçar. Y entonces, el autor cuenta que estaua en los brazos de su madre, mirando la entrada destos Príncipes, porque nació en bíspera de San Sebastián.

Al igual que Marineo, Anglería dejó su huella en Mal Lara tanto por el Opus epistolarum como por la Legatio Babylonica. El primer testimonio se erige como el núcleo medular de un pasaje de la Aplicación. Explica el humanista, teniendo en cuenta el libro XXXV de las Epístolas, el correlato histórico para el mitema presente en el libro I. Caso análogo encontramos en el vocablo parque, en el que, además de referirse al libro XXXVIII de las Epístolas, Mal Lara refleja gráficamente la figura trazada por Anglería a la hora de explicar la ubicación del monasterio de la Cartuja, en Pavía. En el caso de la Legatio, Mal Lara se habrá de valer de la fuente, seleccionando algunos de sus datos, a fin de enriquecer la digressio pertinente. Se observa en la entrada Babylón, en la que describe la Babilonia asiria para seguidamente ampliar la cuestión con una referencia a la ciudad egipcia:

\begin{abstract}
Cibdad principal en Assyria, cabeça de toda la Chaldea. Y de allí se llamó toda la otra parte de Mesopotamia, Babylonia. ... Podian andar por lo alto de los muros carros y auía huertos en ellos y templos. Trata de su grandeza Heródoto, lib. 1; Q. Curcio, lib. 5; Antonio Sabélico, lib. 1, Enneada 1; Strabón, lib. 16. Tenía tezientas [sic] torres, cinquenta puertas de cibdad, todas de metal. Ay otra Babylonia en Egypto, que llaman Alcayro o El Cayro. Trata della Pedro Mártyr en su Legación Babylónica ...
\end{abstract}

Como se ve, tal información obedece a una abbreviatio del libro III, concretamente, de su arranque:

Septimo igitur kalendas februarii hora ante lucana cairum quae alias babilon ab incolis alterius eufratreae babilonis quondam habitata eius imperii caput profecturus alexandria (illis palatinis equitibus quos ad me per soldanum cum edicto regio missos superiore libro diximus et hispanis negociatoribus omnibus quotquot commerciorum causa Alexandriam conuenisse reperi) comitatus discedo ...9

Idéntico procedimiento maneja Mal Lara en bálsamo. A la hora de ofrecer su comentario, sintetiza, de esta manera, un pasaje del libro III de la Legatio: «Un árbol pequeño muy oloroso que nascía solamente en Iudea, de que solía tener el soldado egypto una viña en la Matarea, que estará dies mil pasos del Cayro. Ya está perdido, según dize Pedro Mártyr en el fin de la Legación Babylónicas. La alusión bíblica conjugada con la mención toponímica a Matarea, así como la rareza del bálsamo constituyen elementos extraídos de Anglería:

\begin{abstract}
Ita sole ad occasum vergente Nilum traicimus domumque reuertimur. Postridie vero ab his quibus fuerat a soldano de me cura demandata peto ut ad eum locum ubi christus interea loci dum herodes hierosolimis moraretur latuerat perducerent: tum ut loci numen colerem tum etiam quoniam ibidem balsami arbusta consederant id exoptabam. Eum locum nostra tempestate mataream incolae appellant qui ab urbe cairi passuum milia circiter decem distat. Mercurii igitur die sexto ydus februarii qui nostrae quadragesimae primus eo anno fuit (ubi primum eluxit) mataream versus proficiscimur: palatium primo aspectu et prima fronte regali mole constructum ingredimur: in internis autem dirutum eo quod desertum ex quo balsami arbusta interiere. Illuc enim quo tempore balsamum colligebatur soldani relaxandi animi gratia esse quotannis conferebant. ${ }^{10}$
\end{abstract}

El contenido erudito de la Legatio tiene su aplicación, por último, en la praxis poética. Mal Lara, fascinado por las descripciones de Anglería, acusará así su influencia en La Psique. Entre otros motivos, destaca la narración del viaje relatado como un cronista, a la manera del humanista ítalo; de ahí las referencias geográficas, en la beuresis del texto, a Egipto y al Nilo con sus desembocaduras, en el libro VIII. La peligrosidad de los cocodrilos (205-207), como un detalle en el viaje de la protagonista por Egipto, tiene su correlato en la Legatio. En el pasaje oportuno, recuerda Anglería cómo éstos no resultaban tan feroces en la zona limítrofe entre El Cairo y el

9 Ed. Luis García, Una embajada de los Reyes Católicos a Egipto..., Valladolid, CSIC, 1947, pág. 89.

10 Págs. 179-81. 
mar; pero a medida que el navegante se adentraba en el Nilo, en dirección a las montañas, tales reptiles se hacían más temibles. ${ }^{11}$

Resulta evidente, en suma, cómo los hechos y viajes en la época de los Reyes Católicos nutren la obra de Mal Lara. Se equipara, pues, el sevillano, salvando las distancias, a un cronista que narra los acontecimientos a medio camino entre el mito y la realidad. Como la Legatio, la obra De Orbo Novo Decades del propio Anglería debió estimularle, lo que explicaría las alusiones a las Indias en sus obras de cuño mítico, por ejemplo, en los libros VII o XI de La Psique, con referencias a los pigmeos, las canoas u otros motivos relacionados con la cartografía, o en varias entradas del Hércules, en las que se abordan temas como la tierra dorada o la geografía legendaria del Perú o México. ${ }^{12}$ Todo ello dará pie a Mal Lara, en definitiva, a adentrarse en la descripción históricoetnológica de los pueblos, con una visión universal y erudita digna de uno de los humanistas de mayor vuelo en la España del Renacimiento.

\footnotetext{
11 Pág. 193.

12 Preparamos un estudio sobre la cuestión, en fase avanzada.
} 